\title{
Eğitimcilerin Kaynaştırmaya Yönelik Mesleki Gelişim İhtiyaçları
}

\author{
DOI: $10.26466 /$ opus.845376
}

\author{
İrem Girgin $^{*}$ \\ * Y1. Öğr., Millı̂ Eğitim Bakanlığı, Van/Türkiye \\ E-Posta: iremgrgn.0@gmail.com \\ ORCID: $\quad \underline{0000-0002-5361-9945}$
}

\section{Öz}

Kaynaştırma eğitimi, engelli ve engelsiz öğrencilerin akademik ve sosyal alanlarda tam potansiyellerine ulaşmaları için etkili bir yoldur. Öğretmenlerin kaynaştırma eğitimine yönelik mesleki ihtiyaçlarının araştııılması kaynaştırma faaliyetlerinin etkililiğini artırmak açısından önem taşımaktadır. Dolayısıyla bu çalışmayla, kaynaştırma eğitiminde rol oynayan öğretmenlerin eğitsel ihtiyaçları ile ilgili yapılmış farklı dilde bağımsız çalışmalar bir araya getirilerek, bir sistematik derleme makalesi oluşturulması amaçlanmıştır. Sistematik derleme, klinik bir soruya yanıt ya da probleme çözüm oluşturmak amacıyla alanyazın taranması, eleme kriterleri ile kullanılacak çalışmaların belirlenmesi ve makalenin sonucunda da bu çalışmaların sentezinin sunulmasılyla meydana gelmektedir. Alanyazın taramasi yapılırken, ERIC, Semantic Scholar, Researchgate veri tabanlarmda "teachers' educational needs","," inclusive education", "kaynaştırma" anahtar kelimeleri aratılarak taranmıştır. Bu sistematik derleme çalışmasına dâhil edilen çalışmalar 2009-2020 yılları arasında yayımlanmış çeşitli ülkelerde yazllmış İngilizce ve Türkçe dillerindeki deneysel çalışmalardır. Bu ölçütleri karşıladığı belirtilen 12 deneysel makale incelenmiştir. Alan yazına ilişkin çalışmalar yayınlanma yıllarına göre incelendiğinde, 2014, 2017, 2019 ve 2020 yillarında yapılan çalışmalar fazlalıkta görünmektedir. Incelenen çalışmalarda ağırlıkl olarak nicel çalışma deseninin $(\% 58,3)$, nitel çalışma desenine $(\% 43,7)$ kıyasla daha fazla tercih edildiği görülmüştür. Çalışmalar kullanılan araştırma yöntemlerine göre ele alındığında ise alanyazına ilişkin en çok tercih edilen desenin tarama deseni $(\% 33,3)$ olduğ u bulunmuştur. Alanyazına ilişkin makalelerin hepsinde de eğitimcilerin kaynaştırma eğitiminde daha etkili olabilmesi için, engel türlerine yönelik eğitimlere ihtiyaç duydukları belirtilmiştir.

Anahtar Kelimeler: Kaynaştırma, Öğretmen Eğitimi, Kaynaştırma Ĕ̆itimi. 


\title{
Professional Development Needs of Educator Regarding Inclusive Education
}

\begin{abstract}
Inclusive education is an effective way for both disabled and non-disabled students to fulfill their full potential in academic and social fields. It is important to find out teachers' professional needs for inclusive education to increase the effectiveness of inclusion. Therefore, the aim of this study is to create a systematic review article by bringing together independent studies in different languages on the educational needs of teachers who play a role in inclusive education. Systematic review consists of scanning the literature in order to answer a clinical question or to create a solution to the problem, determining the studies to be used with screening criteria and presenting the synthesis of these studies as a result of the article. Thus, Semantic Scholar, ERIC and Research Gate databases were scanned. Key words for the research were chosen to be "teachers' educational needs", "inclusive education" and "kaynaştırma". As a result, 12 experimental studies in English and Turkish languages were included in this study. Reviewed articles were published in various countries between the years 2009 and 2020. As a result of the analysis, it is seen that the studies carried out in 2014, 2017, 2019 and 2020 are in majority. Also, quantitative research design (58.3\%) was found to be the most preferred research design. On the other hand, the most preferred method related to the literature revealed to be the survey method (33.3\%). In conclusion, it was revealed that educators need trainings for types of disabilities in order to be more effective in inclusive education.
\end{abstract}

Keywords: Inclusion, Teacher education, Inclusive education. 


\section{Giriş}

Kaynaştırma eğitimi, eğitim kurumlarının gerekli destek hizmetlerini sağlamasıyla engelli öğrencilerin normal eğitim sınıflarına yerleştirilmesini ve bu sayede bütün bireylerin eşit eğitimsel fırsatlardan yararlandırılmalarını içerir (Rose, Meyer ve Hitchcock, 2011). Özel eğitimde son yirmi yılda yapılmış olan araştırmalara göre, kaynaştırma eğitimi sadece engelli öğrenciler için değil, tüm öğrenciler için kaliteli bir öğretim ortamı oluşturmaktadır (Vaughn ve Swanson, 2015). Bir diğer deyişle, kaynaştırma, mahalle okullarında yaşa uygun genel eğitim sınıflarında birlikte eğitilen, engelli ve engelsiz öğrenciler için öğrenme toplulukları oluşturarak tüm öğrencilerin ihtiyaçlarını karşılayan okullar yaratmayı amaçlayan bir harekettir (Ferguson, 1996).

Kaynaştırmanın amacı, özel ihtiyaçları olan öğrencilerin başarılı olmaları için ihtiyaç duydukları desteklerle mümkün olduğu kadar uzun bir süre genel eğitim ortamına entegre olmalarını sağlamaktır (Ferguson, Kozleski ve Smith, 2003). Bütün kademelerde yürütülmekte olan kaynaştırma eğitimleri, bireylerin sosyal etkileşimini de sağlamayı dolayısıyla sağlıklı bir eğitim ortamı oluşturmayı amaçlamaktadır. Günümüzde engelli bireylerin özel eğitim sınıflarında yer almasındansa, akranlarıyla bir araya gelebilecekleri kaynaştırma sınıflarında yer alması desteklenmektedir. (Sebba ve Sachdev, 1997; Snyder, 1999).

Kaynaştırma eğitimi içerikte, öğretim yöntemlerinde, yaklaşımlarda ve eğitim stratejilerinde değişiklikler gerektiren bir eğitim sürecini içermektedir ve kaynaştırma eğitiminin başarılı olabilmesi için, eğitimciler başta olmak üzere ailenin ve öğrencilerin de eğitime dâhil olması önem taşımaktadır. Yapılan çalışmalar göstermektedir ki, başarılı bir kaynaştırma eğitiminde eğitimcilerin tutumları ve derse hazırlıkları da eğitimin başarısını etkilemektedir (Gamerous, 1995). Farklı öğrenme ihtiyaçları olan öğrencilerin normal eğitim sınıflarında en iyi ölçüde verim alabilmeleri için gerekli eğitim stratejilerinin planlanmasında okul personelinin, ailenin ve eğitimcilerin işbirlikçi olarak çalışması esastır (Holloway, 2001; Hornby, 2011).

Kaynaştırma eğitiminin yapıldığ1 kurumlarda, öğretmenler arasındaki işbirliği biçimine bağlı olarak kapsayıcı öğrenme ortamlarının geliştirilmesinde yararlı bir etkiye sahip olabileceği belirtilmiştir 
(Hansen, Carrington, Jensen, Molbæk ve Secher Schmidt, 2020). Kaynaştırma eğitiminden söz edildiğinde, farklı bir bakış açısına, birkaç farklı uzman yaklaşımına, bilgi biçimine, beceriye ve yeterliliğe ihtiyaç olduğu ifade edilmiştir. Öğretmenlerin kaynaştırma eğitimine uygun eğitim ortamları geliştirmek için ihtiyaç duyduğu kadar bilgi, yetkinlik ve çeşitli farklı deneyimlere bir anda sahip olması beklenemez (Friend, 2007).

Kaynaştırma eğitimi üzerine yapılmış bazı çalışmalar kaynaştırma eğitiminin özel gereksinimli öğrenciler için sosyal ve akademik anlamda yararlı olduğunu ortaya koymuştur (Cole, Waldron ve Majd, 2004; Nakken ve Pijl, 2002). 2002 yılında yapılan bir çalışmaya göre, kaynaştırma eğitimi öğrenme güçlüğü olan öğrencilerin dil sanatları, matematik, fen bilimleri ve sosyal bilimler alanlarında başarı gösterdiklerini belirtmiştir (Rea, Walter-Thomas ve McLaughlin, 2002). Öte yandan bazı çalışmalar da kaynaştırma eğitimine negatif bir bakış açısıyla yaklaşmıştır. Farrel (2000) çalışmasında, kaynaştırmanın etkililiğine yönelik bazı olumsuz bulguların kaynaştırma eğitiminin doğasından ziyade eğitim ortamındaki öğretimin kalitesiyle daha fazla ilgisi olduğunu öne sürmektedir. 2015 yılında yapılan bir çalışma ortaya koymaktadır ki, kaynaştırma eğitiminin bütün öğrenciler için etkili ve yararlı olabilmesi için daha fazla öğretmen eğitimi gerekmektedir (Moreno, Jaén, Navío ve Moreno, 2015).

Kaynaştırma öğrencileri, yaşıtlarıyla aynı ortamda bulunup, farklı eğitsel ihtiyaçlara sahip olduklarından dolayı, eğitimcilere bu bireylerin eğitsel faaliyetleri konusunda büyük sorumluluklar düşmektedir. Öğretmenlerin sahip oldukları bilgi seviyesi ve mesleki becerileri görevlerini etkili biçimde yapmalarını olumlu yönde etkilemektedir (Tkachyk, 2013). Ayrıca, eğiticilerin etkili bir eğitim ortamı yaratmak için bilgi kaynakları, müfredat ve eğitim teknolojileri hakkında bilgi sahibi olmalarının öğrencilerin yeni bilgiler edinip sentezlemesinde önem taşıdığı belirtilmiştir (Hammond, 1999). Öte yandan, eğitim fırsatlarındaki farklılıklar, yalnızca bireysel kültürel, ekonomik, sağlık veya engellilik koşullarına değil, aynı zamanda coğrafi koşullara ve ülkelerin eğitim sistemlerine de bağlıdır. Bu farklılıklara ek olarak, öğretmenlerin kaliteli eğitim sağlamada çok önemli bir rol oynadığ 1 belirtilmektedir (Florian ve Rouse, 2009). Dolayısıyla öğretmenlerin 
kaynaştırma eğitimine yönelik mesleki ihtiyaçlarının araştırılması kaynaştırma faaliyetlerinin etkililiğini artırmak açısından önem taşımaktadır.

Kaynaştırma eğitiminde öğretmenlerin ihtiyaçları üzerine ülkemizde bazı araştırmalar yapılmıştır. Bunlardan birisi Milli Eğitim Bakanlığı (MEB) bünyesinde Eğitimi Araştırma ve Geliştirme Daire Başkanlığı'nın 2008 yılında yaptığ 1 çalışmadır, bu çalışmada öğretmenlerin kaynaştırma eğitimine yönelik eğitsel ihtiyaçları belirlenmiştir. Çalışmada öğretmenlerin \%47,3'ü özel öğrenme güçlüğü gösteren, dikkat eksikliği ve hiperaktivite bozukluğu olan otistik ve üstün yetenekli çocukların özellikleri konusunda çok, \%43,8'i eğitimleri farklı gelişen çocukların oyun yoluyla eğitimi konusunda kısmen, \%43,5'i özel eğitime muhtaç çocukların ailelerinde gözlenen tepkiler ve çözüm yolları konusunda kısmen, olarak hizmet içi eğitime ihtiyaç duyduklarını belirtmişlerdir (MEB, 2008). Dolayısıyla öğretmenlerin hizmet içi eğitim ihtiyaçlarının araştırılması ve desteklenmesi önem taşımaktadır.

Yapılan araştırmalar öğretmenlerin eğitsel inançlarının ve eğitsel yeterliliklerinin öğretim uygulamalarının önemli belirleyicileri ve yordayıcıları olduğunu ortaya çıkarmıştır (Brownell ve Pajares, 1999). Öte yandan hizmet içi ve hizmet öncesi eğitimler kaynaştırma eğitimlerinin başarılı olmasını desteklemek amacıyla eğitimcilerin gerekli becerileri geliştirilmesi ve bilgiler edinmesi için gereklidir (Mittler, 2000; Flem, Moen ve Gudmondsdottir, 2002).

Aslan (2020) Türkiye'de okul öncesi öğretmenlerinin otizm spektrum bozukluğu olan çocuklarla ilgili kaynaştırma deneyimlerini, karşılaşılan zorlukları ve kullanılan yöntemleri incelediği çalışmasında, öğretmenlerin kaynaştırma sürecini başarılı bir biçimde yönetmek için, mesleki yeterliliklerinin geliştirilmesine ihtiyaçları olduğunu belirtmiştir. 2007'de yapılmış olan bir çalışmada ise, kaliteli öğretmen eğitimi programlarının eğiticilerin kaynaştırma eğitimine ilişkin rollerini olumlu yönde etkileyebileceği ifade edilmiştir (Stella, Forlin ve Lan, 2007).

Yapılan çalışmalar göstermektedir ki kaynaştırma eğitimi hem engelli öğrenciler için hem de normal öğrenciler için önem göstermektedir. Ayrıca etkili kaynaştırma uygulamalarının yapılabilmesi için öğretmenlerin kaynaştırma eğitimine yönelik eğitim alması 
gerekebilmektedir. Dolayısıyla öğretmenlerin kaynaştırmaya yönelik eğitsel ihtiyaçlarının incelenmesi önem taşımaktadır.

Kaynaştırma eğitimi üzerine yapılmış çokça çalışma olmasına rağmen, alanyazında öğretmenlerin kaynaştırma eğitimine yönelik mesleki gelişim ihtiyaçları ile ilgili bir sistematik derleme makalesi bulunmamaktadır. Eğitimcilerin kaynaştırma eğitimine yönelik mesleki gelişim ihtiyaçlarını bir araya getiren bu çalışma ile alanyazındaki boşluğu doldurmak amaçlanmıştır.

\section{Yöntem}

\section{Çalışmanın türü}

$\mathrm{Bu}$ çalışmanın amacı kaynaştırma eğitimi veren öğretmenlerin duydukları mesleki gelişim ihtiyaçlarını ele alacak ve bu konuda genel bir profil oluşturmaya yardımcı olacak bir sistematik derleme çalışması ortaya koymaktır. Sistematik derlemeler, alanyazın hakkında, daha önce neler yapıldığını, nasıl araştıııldığını ve kilit konuların neler olduğunu ortaya koyduğundan dolayı değerli çalışmalardır (Hart,2001). Sistematik derlemelerin diğer çalışmalardan ayrılmasını sağlayan benzersiz özelliklerinden birisi de, daha önce alanyazında yapılmış çalışmaların etkilerini ortaya koymadaki güce sahip olmaları olarak belirtilmiştir (Mulrow, 1994).

\section{Veri Toplama}

Çalışmada çeşitli ülkelerde kaynaştırma eğitiminde yer alan eğitimcilerin mesleki ihtiyaçlarını konu alan çalışmalar ele alınmıştır. Konu küresel olarak ele alınmak istendiğinden uluslararası çapta makaleler, İngilizce dilinde olmak üzere incelenmiştir. Makale taraması, ERIC, Semantic Scholar ve Researchgate veri tabanlarından yapılmıştır. Makale taramasinda kullanilan anahtar kelimeler "teachers' educational needs", "inclusive education" olarak belirlenmiştir. Ortaya çıkan yayınlardan 2009-2020 yılları arasında yayınlanmış olan makaleler seçilmiş, konuyla alakalı tezler çalışmaya dâhil edilmemiştir. İlk aşamada ERIC tarama motorundan 94.054 sonuç arasından belirlenen kriterlere uyan 194 adet 
çalışma, Semantic Scholar kaynağından 78.000 sonuç arasından 178 adet makale, Researchgate veri tabanından 86.000 sonuç arasından 191 adet çalışma seçilmiştir. Bu derlemeye nicel ve nitel araştırma yöntemlerinden deneysel desenli, tarama desenli, vaka çalışma desenli makaleler dâhil edilmiştir. Makale eleme süreci sonunda elde kalan 12 adet çalışma üzerinden sistematik derleme çalışmasının yapılmasına karar verilmiştir.

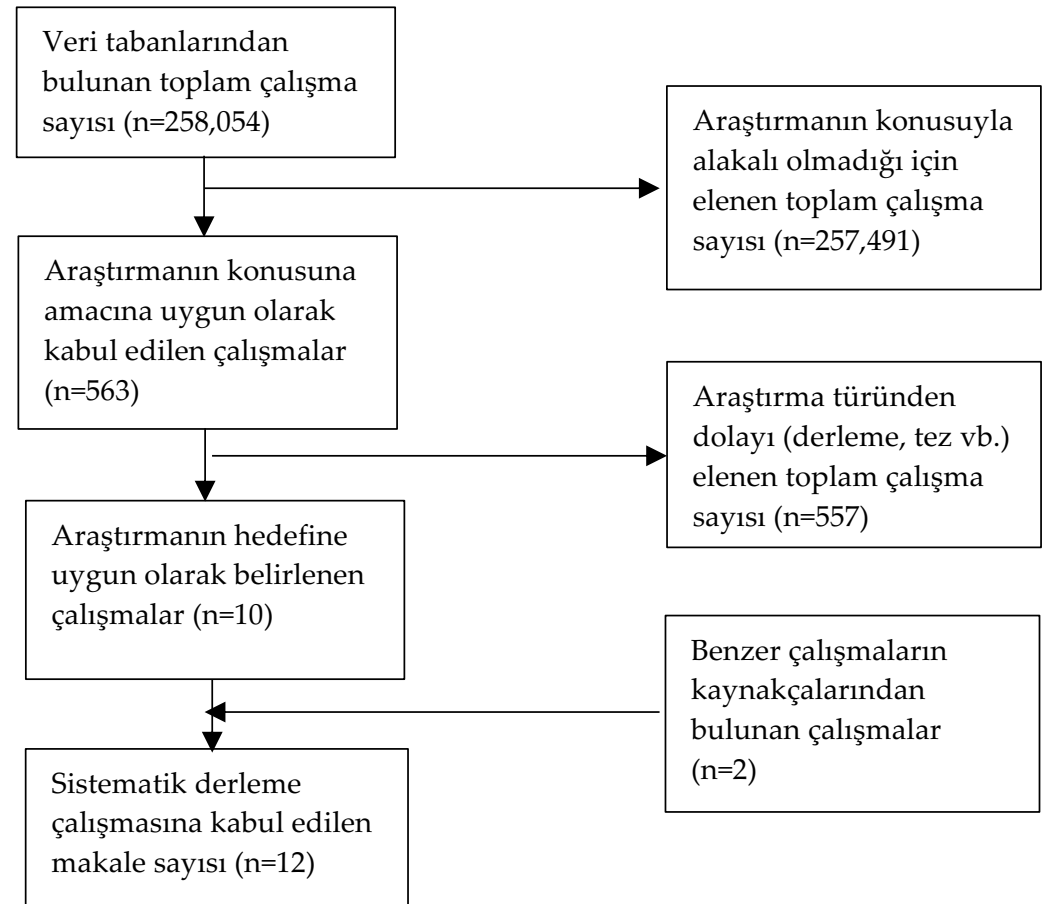

Şekil 1. Sistematik Derleme Sürecinin Özeti

\section{Bulgular}

Eleme aşamalarının sonucunda, 12 adet makale üzerinden sistematik derleme çalışmasının yapılmasına karar verilmiştir. Tablo 1 bu çalışmaların başlıklarını, yürütüldükleri ülkeleri, örneklemlerini ve bu çalışmalarda incelenen değişkenleri içermektedir. Makalelerin hepsinde de eğitimcilerin kaynaştırma eğitiminde daha etkili olabilmek için, engel 
türlerine yönelik eğitimlere ihtiyaç duydukları belirtilmiştir (Akalın, Demir, Sucuoğlu, Bakkaloğlu ve İşcen, 2014; Chitiyo, Kumedzro, Hughes, Ahmed, 2019; Chitiyo, Hughes, Chitiyo, Changara, Phiri, Haihambo, Taukeni ve Dzenga, 2019; Aktan, 2020; Pınar, 2014; Moriña, Perera ve Carballo, 2020).

Tablo 1. Derlemede kullanılan çalışmalar

\begin{tabular}{|c|c|c|c|}
\hline Çalışmanın Adı & $\begin{array}{l}\text { Çalışmanın } \\
\text { YürütüldügüüÜlke }\end{array}$ & $\begin{array}{l}\text { Örneklem } \\
\text { (n) }\end{array}$ & Değişkenler \\
\hline $\begin{array}{l}\text { Determination of } \\
\text { Educational Needs of } \\
\text { Teachers Regarding the } \\
\text { Education of Inclusive } \\
\text { Students with Learning } \\
\text { Disability }\end{array}$ & Türkiye & 20 & $\begin{array}{l}\text { Kaynaştırma öğrencilerinin eğitiminde alternatif } \\
\text { değerlendirme araçlarına yönelik eğitim, } \\
\text { ögrenme güçlüğüyle alakalı engellerin } \\
\text { tanınmasına yönelik eğitimler,okul yönetimi ve } \\
\text { rehberlik ve araştırma merkezlerinden destek } \\
\text { alma ihtiyacı. }\end{array}$ \\
\hline $\begin{array}{l}\text { Identification of inclusive } \\
\text { education classroom } \\
\text { teacher's views and needs } \\
\text { regarding in-service } \\
\text { training on special } \\
\text { education in Turkey }\end{array}$ & Türkiye & 222 & $\begin{array}{l}\text { Özel gereksinimli öğrencilere ilişkin genel } \\
\text { bilgilendirme, aile hizmetleri ve mevzuata } \\
\text { ilişkin bilgilendirme, öğretim, değerlendirme } \\
\text { yöntemlerine ilişkin eğitim, davranış kontrolü } \\
\text { eğitimi, BEP hazırlama ve akademik beceri } \\
\text { eğitimi, akademik olmayan becerilerin eğitimi. }\end{array}$ \\
\hline $\begin{array}{l}\text { İlköğretim Okullarında } \\
\text { Görev Yapan Sınıf } \\
\text { Öğretmenlerinin Hizmet içi } \\
\text { Eğitim İhtiyaçları }\end{array}$ & Türkiye & 90 & $\begin{array}{l}\text { Dikkat eksikliği, öğrenme güçlüğü, } \\
\text { hiperaktivite, üstün yetenekli çocuklar } \\
\text { konularında hizmet içi eğitimler }\end{array}$ \\
\hline $\begin{array}{l}\text { Sınıf Öğretmenlerinin Özel } \\
\text { Öğrenme Güçlüğü Olan } \\
\text { Öğrencilerin Eğitsel } \\
\text { Değerlendirme ve Eğitimsel } \\
\text { Müdahale Sürecinde Görüş } \\
\text { ve Uygulamaları }\end{array}$ & Türkiye & 8 & $\begin{array}{l}\text { Eğitimsel müdahale programlarına yönelik } \\
\text { eğitimler. }\end{array}$ \\
\hline $\begin{array}{l}\text { The Needs of Inclusive } \\
\text { Preschool Teachers about } \\
\text { Inclusive Practices }\end{array}$ & Türkiye & 40 & $\begin{array}{l}\text { Özel gereksinimli öğrencilerin karakteristik ve } \\
\text { gelişimsel özellikleri ile ilgili eğitimler, davranış } \\
\text { kontrolü eğitimi, BEP hazırlama eğitimi, eğitim } \\
\text { ortamında kaynaştırma öğrencisi için gerekli } \\
\text { eğitim materyallerinin eksikliği. }\end{array}$ \\
\hline $\begin{array}{l}\text { Teachers' Professional } \\
\text { Development Needs } \\
\text { Regarding Inclusive } \\
\text { Education in Ghana }\end{array}$ & Gana & 250 & $\begin{array}{l}\text { Öğretmenler için sosyal becerieğitimi, } \\
\text { fonksiyonel becerilerin öğretimine yönelik } \\
\text { eğitim, değerlendirme yöntemleri ile ilgili } \\
\text { eğitimler, eğitim ortamında kaynaştırma } \\
\text { öğrencisi için gerekli eğitim materyallerinin } \\
\text { eksikliği. }\end{array}$ \\
\hline $\begin{array}{l}\text { Training needs of } \\
\text { Academics on Inclusive } \\
\text { Education and Disability }\end{array}$ & İspanya & 20 & $\begin{array}{l}\text { Engel türlerine yönelik eğitimler, mesleki } \\
\text { becerilerin geliştirilmesine yönelik eğitimler, } \\
\text { kurumsal destek ihtiyacı, pratik bilgi eğitimi, } \\
\text { destek servisleri ve engellilere yönelik mevzuat } \\
\text { hakkında eğitimler }\end{array}$ \\
\hline $\begin{array}{l}\text { Exploring Teachers' Special } \\
\text { and Inclusive Education } \\
\text { Professional Development } \\
\text { Needs in Malawi, Namibia } \\
\text { and Zimbabwe }\end{array}$ & $\begin{array}{l}\text { Malavi, Namibia } \\
\text { ve Zimbabwe }\end{array}$ & 629 & $\begin{array}{l}\text { Özel gereksinimli öğrencilerin ihtiyaçlarına } \\
\text { ilişkin eğitim, genel özel eğitime yönelik } \\
\text { eğitimler, öğrenme güçlüğüne yönelik eğitimler, } \\
\text { duyusal engellerle ilgili eğitimler, davranış } \\
\text { kontrolü eğitimleri, destek sinıf materyalleri. }\end{array}$ \\
\hline
\end{tabular}




\begin{tabular}{|c|c|c|c|}
\hline $\begin{array}{l}\text { Teachers talk about } \\
\text { inclusion... but can they } \\
\text { implement it in their } \\
\text { classroom? Exploring } \\
\text { teachers' views on inclusion } \\
\text { in a Scottish secondary } \\
\text { school }\end{array}$ & İskoçya & 88 & $\begin{array}{l}\text { Öğretmenlerin özel gereksinim öğrencilere } \\
\text { ilişkin öğretmen eğitiminde duydukları } \\
\text { eksiklikler ve özgüven yetersizliği. }\end{array}$ \\
\hline $\begin{array}{l}\text { Teachers' perceptions on } \\
\text { inclusion in basic school }\end{array}$ & $\begin{array}{l}\text { Brezilya ve } \\
\text { Portekiz }\end{array}$ & 303 & $\begin{array}{l}\text { Özel gereksinimli öğrencilerin eğitiminde } \\
\text { kullanılacak destek materyallerine (oyunlar, } \\
\text { cihazlar, yazılımlar ve yardımcı teknolojiler) } \\
\text { yönelik eğitimler, kaynaştırma öğrencilerine } \\
\text { yönelik genel öğretim yöntemleri ve stratejileri } \\
\text { konusunda eğitimler. }\end{array}$ \\
\hline $\begin{array}{l}\text { Zimbabwean Early } \\
\text { Childhood Education } \\
\text { Special Needs Education } \\
\text { Teacher Preparation for } \\
\text { Inclusion }\end{array}$ & Zimbabwe & 28 & $\begin{array}{l}\text { Öğretmenlik eğitiminde kaynaştırma eğitiminin } \\
\text { yeterli biçimde ele alınmamış olması, } \\
\text { kaynaştırma eğitimine yönelik yetersizlik } \\
\text { hissetme. }\end{array}$ \\
\hline $\begin{array}{l}\text { Voices of experience: } \\
\text { general education teachers } \\
\text { on teaching students with } \\
\text { disabilities }\end{array}$ & Amerika & 46 & $\begin{array}{l}\text { Bu çalışmada şehirde çalışan öğretmenler, } \\
\text { kaynaştırma öğretimi için bilgi ve becerilerinin } \\
\text { yetersiz olduğunu düşünmüş ve öğretmenlik } \\
\text { eğitimleri konusunda oldukça olumsuz } \\
\text { görüşlere sahip olmuşlardır. Kaynaştırma } \\
\text { eğitimi sürecinde davranış yönetimi konusunda } \\
\text { yetersizlikler. }\end{array}$ \\
\hline
\end{tabular}

İncelenen çalışmaların yürütüldügü ülkeler arasında Türkiye, Gana, İspanya, Malawi, Namibia, Zimbabwe, Amerika, Brezilya ve İskoçya bulunmaktadır. En düşük örneklemin Türkiye'de yapılmış olan çalışmada bulunduğu dikkat çekmektedir. En büyük örneklem Malawi, Namibia ve Zimbabwe'de yapılmış olan çalışmada olmakta olup, çalışma toplam 629 kişiden oluşmaktadır.

Pınar (2014), çalışmasında kaynaştırma sınıfında çalışan öğretmenlerin özel eğitime yönelik hizmet içi eğitim ihtiyaçlarını araştırmıştır, çalışmada Identification Tool for Teachers' In-Service Training Needs ölçeği kullanılmıştır. Araştırmanın çalışma grubu 2014 yılında Bolu ilinde görev yapmakta olan 222 ilkokul öğretmenidir. Verilerin analizi SPSS 21.0 uygulamasında yapılmıştır. Veri analizi sonucu elde edilen sonuçlara göre öğretmenlerin, özel gereksinimli öğrencilere yönelik genel bilgilendirme, aile hizmetleri ve mevzuata yönelik bilgilendirme, öğretim, değerlendirme ve davranış kontrolü eğitimi, BEP hazırlama ve akademik beceri eğitimi, akademik olmayan becerilerin eğitimi alanlarında hizmet içi eğitim almak istedikleri belirtilmiştir (Pınar, 2014). 
2017 yılında yapılan bir çalışmada ise, sınıf öğretmenlerinin eğitimsel müdahale sürecinde görüşleri ölçülmüştür. Çalışmada, yarı yapılandırılmış görüşme ve gözlem teknikleri kullanılmıştır. Araştırmanın çalışma grubu 2015-2016 akademik yılında görev yapmış olan 8 ilkokul öğretmeninden oluşmaktadır. Verilerin analizi yapılırken sürekli karşılaştırmalı analiz yöntemi kullanılmıştır. Analizin sonuçlarına göre, öğretmenlerin özel gereksinimli bir bireyin eğitimi için yeterli bilgi sahibi olmadıkları, öğretmenlerin özel öğrenme güçlüğü olan bir öğrenci için müdahale programı hazırlamada yetersiz oldukları ortaya çıkmıştır (Çakıroğlu ve Kuruyer, 2017).

Moriña, Perera ve Carballo (2020) çalışmalarında akademisyenlerin kaynaştırma eğitimi ve engeller eğitimine ilişkin eğitsel ihtiyaçlarını ölçmüştür. İspanya'da çalışan 20 akademisyenin katıldığı araştırmada yarı yapılandırılmış görüşmeler ve açık uçlu sorular kullanılmıştır. Veri analizi sonucunda akademisyenlerin engelli bireylerin eğitimi konusunda yeterli mesleki becerilere ve bilgilere sahip olmadıkları; kaynaştırma eğitimine yönelik hizmet içi eğitime ihtiyaç duydukları belirlenmiştir. Ayrıca katılımcıların pratik bilgi eğitimi, destek servisleri ve engellilere yönelik mevzuat konularına ilişkin eksiklikleri olduğu ve bu konularda eğitim almak istedikleri ortaya çıkmıştır (Moriña, Perera ve Carballo, 2020).

Aktan (2020), çalışmasında öğretmenlerin öğrenme güçlüğü olan kaynaştırma öğrencilerinin eğitimine yönelik eğitsel ihtiyaçlarını incelemiştir. Araştırmada durum çalışması deseni tercih edilmiştir. Çalışmanın grubu, Düzce'de 2018-2019 akademik yılı içerisinde çeşitli kademelerde görev yapan 20 öğretmenden oluşmaktadır. Veri toplama yöntemi olarak yapılandırılmış görüşme yöntemi kullanılmıştır. Verilerin analizinde içerik analizi yöntemi kullanılmıştır. Araştırmanın sonuçlarına göre, öğretmenlerin kaynaştırma öğrencilerinin eğitiminde alternatif değerlendirme araçları, öğrenme güçlüğü ve engellerin tanınması konularında hizmet içi eğitimlere ihtiyaç duydukları belirlenmiştir. Bunlara ek olarak katılımclar kaynaştırma öğrencileri için okul yönetimi ve rehberlik ve araştırma merkezlerinden destek alma ihtiyacı duyduklarını da belirtmiştir (Aktan, 2020).

2012 yılında yapılmış olan bir çalışmada, ilköğretim okullarında görev yapan sınıf öğretmenlerinin hizmet içi eğitim ihtiyaçları 
incelenmiştir. Bu çalışmada Ankara ilinde 2008-2009 akademik yılında görev yapmakta olan 90 öğretmenden İlköğretim okullarında görev yapan sınıf öğretmenlerinin hizmet içi eğitim ihtiyaçlarının belirlenmesi ölçeği kullanılarak veri toplanmıştır. Verilerin analizinde SPSS 16.0 kullanılmıştır. Veri analizinden elde edilen sonuçlara göre, öğretmenlerin dikkat eksikliği, öğrenme güçlüğü, hiperaktivite, üstün yetenekli çocuklar konularında hizmet içi eğitimlere ihtiyaç duydukları ortaya çıkmıştır (Ergin, Akseki ve Deniz,2012).

2019 yılında yapılmış olan bir çalışmada ise, Malawi, Zimbabwe ve Namibia' da yaşayan öğretmenlerin özel eğitim ve kaynaştırma eğitimine ilişkin profesyonel gelişim ihtiyaçları araştırılmıştır. Malawi'den 300 öğretmenin, Namibia'dan 125 öğretmenin ve Zimbabwe'den 204 öğretmenin katılımcı olduğu çalışmada veri toplama yöntemlerinden açık uçlu ve kapalı uçlu sorular kullanılmıştır. Veri analizi sonucunda, öğretmenlerin özel gereksinimli öğrencilerin eğitsel ihtiyaçlarına yönelik, genel özel eğitime yönelik, öğrenme güçlügüne yönelik, duyusal engellerle ilgili ve davranış kontrolüne yönelik eğitimlere ihtiyaç duydukları belirlenmiştir. Katılımcılar destek sınıf materyallerinde eksiklik duyulduğunu da ifade etmişlerdir (Chitiyo vd, 2019).

Chitiyo, Kumedzro, Hughes ve Ahmed, 2019 yilında yapmış oldukları çalışmada, Gana'daki öğretmenlerin kaynaştırma eğitimine ilişkin mesleki gelişim ihtiyaçlarını incelemişlerdir. Araştırmanın çalı̧̧ma grubu 2019 yılında Gana'da görev yapmış olan 250 öğretmendir. Çalışmada veri toplamak için anket yöntemi tercih edilmiştir. Verilerin analizinde SPSS programı kullanılmıştır. Çalışmanın sonuçlarına göre, öğretmenlerin, sosyal beceri öğretmen eğitimi, fonksiyonel becerilerin öğretimine yönelik eğitim, değerlendirme yöntemleri ile ilgili eğitimler alanlarında eksiklik gösterdiği ve hizmet içi eğitimlere ihtiyaçları olduğu ortaya çıkmıştır. Çalışmada ayrıca bir kaynaştırma öğrencisinin eğitimi için gerekli eğitim materyallerinde eksiklik olduğu belirtilmiştir (Chitiyo vd., 2019).

2014 yılında yapılmış olan bir çalışmada, okul öncesi öğretmenlerinin kaynaştırma eğitimine yönelik ihtiyaçları incelenmiştir. Araştırmada yarı yapılandırılmış görüşmeler kullanılarak Ankara'da 2014 yılında görev yapmış olan 40 öğretmenden veri toplanmıştır. Verilerin analizinde QSR NVivo9 programı kullanılmıştır. Veri analizinden elde edilen sonuçlara 
göre, okul öncesi öğretmenlerinin, özel gereksinimli öğrencilerin karakteristik ve gelişimsel özellikleri ile ilgili eğitimlere, davranış kontrolü eğitimine ve BEP hazırlama eğitimine ihtiyaç duydukları ortaya çıkmıştır. Bu araştırmada aynı zamanda kaynaştırma öğrencisi için gerekli olan materyaller konusunda eksiklik yaşadığı belirlenmiştir (Akalın vd., 2014).

Majoko (2017) Zimbabwe'de yapmış olduğu çalışmada, Zimbabwe'li okul öncesi özel eğitim öğretmenlerinin kaynaştırmaya yönelik hazırlanmalarını incelemiştir. 28 öğretmenin yer aldığ 1 bu çalışmada, nitel araştırma yöntemlerinden teori oluşturma yöntemi kullanılmıştır. Çalışmada veri toplama aracı olarak yarı yapılandırılmış görüşme yöntemi kullanılmıştır. Veri analizinde sabit karşılaştırma yöntemi kullanılmıştır. Araştırmanın sonuçlarına göre, eğitimciler kaynaştırma eğitimine hazırlıklı olmadıklarını belirtmişlerdir. Öğretmenler ayrıca, öğretmen eğitiminde, gerekli teknolojik aletlerin sağlanmasının, ebeveynler, doktorlar ve terapistler gibi profesyonellerle iş birliği içinde olmanın kaynaştırma eğitimini daha etkili kılacağını düşündüklerini belirtmişlerdir (Manrique, Frere, Moreira ve Arezes, 2018).

İskoçya'da yapılan bir çalışmada öğretmenlerin kaynaştırma eğitimini sınıfa entegre edebilmelerine yönelik görüşleri incelenmiştir. Çalışmanın örneklemi 88 ortaokul öğretmeninden oluşmaktadır. Araştırmada nicel araştırma yöntemlerinden tarama deseni kullanılmıştır. Veri toplama aracı olarak JISC Online Survey çevrimiçi programından 14 soruluk açık uçlu ve kapalı uçlu sorular içeren bir anket oluşturularak kullanılmıştır. Veri analizinden elde edilen sonuçlara göre, öğretmenlerin \%64'ü kaynaştırma eğitimine yönelik yeterli bir eğitim almadıklarını ifade etmiştir. Ayrıca, öğretmenler özel gereksinimli öğrencilerle ilgili yeterli bilgiye sahip olmadıklarından dolayı özgüven eksikliği yaşadıklarını da belirtmişlerdir (Ferriday ve Cantali, 2020).

2019 yılında yapılmış olan bir çalışmada, öğretmenlerin temel eğitim okullarındaki kaynaştırma eğitimine ilişkin algıları incelenmiştir. Çalışmanın örneklemi São Paulo'da ilkokul ortaokul ve yetişkin eğitimi kademelerinde göre yapan 197 matematik öğretmeni ve Kuzey Portekiz'in Braga, Barcelos, Guimarães ve Viana do Castelo şehirlerinde ilkokul ve ortaokul kademelerinde çalışan 106 matematik öğretmeninden oluşmaktadır. Veri toplama aracı olarak 48 soruluk bir anket 
kullanılmıştır. Veri analizinde kapalı uçlu sorular için Microsoft Excel kullanılmıştır. Açık uçlu sorulardan elde edilen verilerin analizinde içerik analizi yöntemi kullanılmıştır. Araştırmanın sonuçlarına göre, öğretmenlerin özel gereksinimli öğrencilerin eğitiminde kullanılacak destek materyalleri (oyunlar, cihazlar, yazılımlar ve yardımcı teknolojiler) konusunda eğitim almaları gerektiği ifade edilmiştir. Ayrıca, öğretmenlerin kaynaştırma öğrencilerine yönelik genel öğretim yöntemleri ve stratejileri konusunda bilgi eksiklikleri olduğu belirtilmiştir (Manrique, Dirani, Frere, Moreira ve Arezes, 2018).

Berry, 2011 yılında yaptığı çalışmasında, genel eğitim sınıflarındaki öğretmenlerin özel gereksinimli öğrencilere yönelik eğitsel ihtiyaçlarını incelemiştir. Çalışmada araştırma yöntemlerinden odak grup yöntemi kullanılmıştır. Çalışmanın örneklemi toplam 46 ilkokul öğretmeninden oluşmaktadır. 46 öğretmenden 11 tane öğretmen kırsal bölgede,, 18 öğretmen banliyöde ve $17^{\prime}$ si de şehirde görev yapmaktadır. Veri toplamak için anket ve verilerin analizi için SPSS programı kullanılmıştır. Araştırmanın sonuçlarına göre, öğretmenler kaynaştırma öğretimi için bilgi ve becerilerinin yetersiz olduğunu ve öğretmenlik eğitimleri konusunda olumsuz görüşlere sahip olduklarını belirtmişlerdir. Ayrıca, kaynaştırma eğitimi sürecinde davranış yönetimi konusunda problemler yaşadıklarını da belirtmişlerdir (Berry, 2011).

\section{Tablo 2. Kaynaştırma eğitimine yönelik eğitsel ihtiyaçlar}

\begin{tabular}{|c|c|}
\hline Çalışmalar & Değişkenler \\
\hline $\begin{array}{l}\text { Determination of Educational Needs of } \\
\text { Teachers Regarding the Education of } \\
\text { Inclusive Students with Learning Disability }\end{array}$ & $\begin{array}{l}\text { Kaynaştırma öğrencilerinin eğitiminde alternatif } \\
\text { değerlendirme araçlarına yönelik eğitim } \\
\text { Öğrenme güçlüğüyle alakalı engellerin tanınmasına yönelik } \\
\text { eğitim }\end{array}$ \\
\hline $\begin{array}{l}\text { Identification of inclusive education } \\
\text { classroom teacher's views and needs } \\
\text { regarding in-service training on special } \\
\text { education in Turkey }\end{array}$ & $\begin{array}{l}\text { Özel gereksinimli öğrencilere ilişkin eğitim } \\
\text { Aile hizmetleri ve mevzuata ilişkin eğitim } \\
\text { Değerlendirme yöntemlerine ilişkin eğitim } \\
\text { Davranış kontrolü eğitimi } \\
\text { BEP hazırlama eğitimi } \\
\text { Akademik ve akademik olmayan beceri eğitimi }\end{array}$ \\
\hline $\begin{array}{l}\text { İlköğretim Okullarında Görev Yapan Sınıf } \\
\text { Öğretmenlerinin Hizmetiçi Eğitim İhtiyaçları }\end{array}$ & $\begin{array}{l}\text { Dikkat eksikliği ve hiperaktivite bozukluğuna ilişkin eğitim } \\
\text { Öğrenme güçlügüne ilişkin eğitim } \\
\text { Üstün yetenekli bireylere ilişkin eğitim }\end{array}$ \\
\hline $\begin{array}{l}\text { Sınıf Öğretmenlerinin Özel Öğrenme } \\
\text { Güçlüğü Olan Ö̈̆rencilerin Eğitsel } \\
\text { Değerlendirme ve Eğitimsel Müdahale } \\
\text { Sürecinde Görüş ve Uygulamaları }\end{array}$ & Eğitimsel müdahale programlarına ilişkin eğitim \\
\hline
\end{tabular}




\begin{tabular}{|c|c|}
\hline about Inclusive Practices & $\begin{array}{l}\text { özelliklerine ilişkin eğitimler } \\
\text { Davranış kontrolü eğitimi } \\
\text { BEP hazırlama eğitimi }\end{array}$ \\
\hline $\begin{array}{l}\text { Teachers' Professional Development Needs } \\
\text { Regarding Inclusive Education in Ghana }\end{array}$ & $\begin{array}{l}\text { Öğretmenler için sosyal beceri eğitimi } \\
\text { Fonksiyonel becerilerin öğretimine ilişkin eğitim } \\
\text { Değerlendirme yöntemlerine ilişkin eğitim }\end{array}$ \\
\hline $\begin{array}{l}\text { Training needs of Academics on Inclusive } \\
\text { Education and Disability }\end{array}$ & $\begin{array}{l}\text { Engel türlerine yönelik eğitim } \\
\text { Mesleki becerilerin geliştirilmesine yönelik eğitim } \\
\text { Pratik bilgi eğitimi } \\
\text { Destek servisleri eğitimi } \\
\text { Engellilere yönelik mevzuata yönelik eğitim }\end{array}$ \\
\hline $\begin{array}{l}\text { Exploring Teachers' Special and Inclusive } \\
\text { Education Professional Development Needs } \\
\text { in Malawi, Namibia and Zimbabwe }\end{array}$ & $\begin{array}{l}\text { Özel gereksinimli öğrencilerin eğitsel ihtiyaçlarına yönelik } \\
\text { eğitim } \\
\text { Özel eğitime ilişkin eğitim } \\
\text { Öğrenme güçlüğüne ilişkin eğitim } \\
\text { Duyusal engele ilişkin eğitim } \\
\text { Davranış kontrolü eğitimi }\end{array}$ \\
\hline $\begin{array}{l}\text { Teachers talk about inclusion... but can they } \\
\text { implement it in their classroom? Exploring } \\
\text { teachers' views on inclusion in a Scottish } \\
\text { secondary school }\end{array}$ & Özel gereksinimli öğrencilere ilişkin eğitim \\
\hline $\begin{array}{l}\text { Teachers' perceptions on inclusion in basic } \\
\text { school }\end{array}$ & $\begin{array}{l}\text { Özel gereksinimli öğrencilerin eğitiminde kullanılan ders } \\
\text { materyallerine ilişkin eğitim } \\
\text { Kaynaştırma öğrencilerine ilişkin genel öğretim yöntemleri } \\
\text { konusunda eğitim }\end{array}$ \\
\hline $\begin{array}{l}\text { Zimbabwean Early Childhood Education } \\
\text { Special Needs Education Teacher Preparation } \\
\text { for Inclusion }\end{array}$ & Kaynaştırma eğitimine ilişkin eğitim \\
\hline $\begin{array}{l}\text { Voices of experience: general education } \\
\text { teachers on teaching students with disabilities }\end{array}$ & Davranış kontrolü eğitimi \\
\hline
\end{tabular}

\section{Eğitimcilerin kaynaştırma eğitimine ilişkin eğitsel ihtiyaçları Tablo 2 'de sunulmuştur.}

Tablo 3. Ĕ̆itsel İhtiyaçların Analizi

\begin{tabular}{lll}
\hline Eğitsel ihtiyaçlar & f & $\%$ \\
\hline Kaynaştırma eğitiminde alternatif değerlendirme araçlarına & 3 & 25 \\
yönelik eğitim & & \\
Özel gereksinimli öğrencilere ilişkin eğitim & 4 & 33,3 \\
Kaynaştırma eğitimine ilişkin eğitim & 2 & 50 \\
Öğrenme güçlügüne yönelik eğitim & 3 & 25 \\
Dikkat eksikliği ve hiperaktivite bozukluğuna ilişkin eğitim & 1 & 8,3 \\
Duyusal engelli bireylere ilişkin eğitim & 1 & 8,3 \\
Üstün yetenekli bireylere ilişkin eğitim & 1 & 8,3 \\
Davranış kontrolü eğitimi & 4 & 33,3 \\
BEP hazırlama eğitimi & 2 & 16,6 \\
Öğretmenlere yönelik beceri eğitimi & 3 & 25 \\
Aile hizmetlerine ilişkin ve engelli öğrenci mevzuatına ilişkin & 2 & 16,6 \\
eğitim & & \\
Eğitimsel müdahale programı eğitimi & 1 & 8,3 \\
Pratik bilgi eğitimi & 1 & 8,3 \\
Destek servislerine ilişkin eğitim & 1 & 8,3 \\
\hline
\end{tabular}


Yapılan analiz sonucunda eğitimcilerin kaynaştırmaya ilişkin mesleki gelişim ihtiyaçları Tablo 3 'te verilmiştir. İncelenen çalışmaların $\% 50$ 'sinde eğitimciler kaynaştırma eğitimine yönelik eğitime ihtiyaç duyduklarını belirtmişlerdir. Çalışmaların \%33,3'ünde eğitimciler özel gereksinimli öğrencilere ilişkin eğitim konusunda ve davranış kontrolü konularında eksiklik hissettiklerini ifade etmişlerdir.

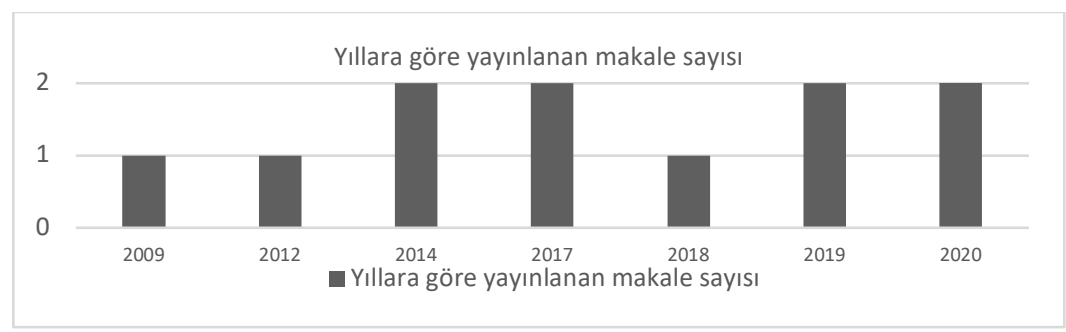

Şekil 2. Yıllara göre makaleler

Öğretmenlerin kaynaştırmaya yönelik mesleki ihtiyaçlarına ilişkin çalışmalar çoğunlukla 2014, 2017, 2019 ve 2020 yıllarında yapılmıştır.

Tablo 4 Çalışmaların yürütülddüğü ülkeler

\begin{tabular}{lll}
\hline Ülkeler & Çalışma Sayıları(f) & $\%$ \\
\hline Türkiye & 5 & 41,6 \\
İspanya & 1 & 8,3 \\
Gana & 1 & 8,3 \\
Malawi, Zimbabwe ve Namibia & 2 & 16,6 \\
Amerika & 1 & 8,3 \\
İskoçya & 1 & 8,3 \\
Brezilya ve Portekiz & 1 & 8,3 \\
\hline
\end{tabular}

Tablo 4'te görülen oranlara göre, kaynaştırma eğitimi veren eğitimcilerin eğitsel ihtiyaçları üzerine 2012-2020 yılları arasında en çok çalışma Türkiye'de $(\% 41,6)$ yapılmıştır. Bu çalışmaları Zimbabwe'de $(\% 16,6)$ yapılmış olan 2 adet çalışma izlemektedir.

Tablo 5 'te görüldüğü üzere, alanyazındaki çalışmalar kullanılan araştırma modelleri bakımından değerlendirildiğinde, nitel araştırma modelindeki çalışmaların $(\% 58,3)$ daha çok yapılmış olduğu görülmektedir. 
Tablo 5. Kullanılan araştırma modelleri

\begin{tabular}{lll}
\hline Araştırma modelleri & f & \% \\
\hline Nicel araştırma deseni & 7 & 58,3 \\
Nitel araştırma deseni & 5 & 41,7 \\
\hline Toplam & 12 & 100.0 \\
\hline
\end{tabular}

Tablo 6. Çalışmalarda kullanılan araştırma yöntemleri

\begin{tabular}{lll}
\hline Yöntem & $\mathrm{f}$ & $\%$ \\
\hline Betimsel desen & 2 & 16,6 \\
Tarama deseni & 4 & 33,3 \\
Odak grup yöntemi & 1 & 8,3 \\
Örnek olay incelemesi & 3 & 25 \\
Teori oluşturma & 2 & 16,6 \\
Toplam & 12 & 100 \\
\hline
\end{tabular}

Çalışmalar kullanılan yöntemler bakımından değerlendirildiğinde, tarama deseninin $(\% 33,3)$ diğer araştırma yöntemlerine kıyasla daha fazla kullanıldığı bulunmuştur. Ardından örnek olay incelemesinin (\%25) sıklıkla kullanıldığı görülmüştür.

\section{Tartışma ve Sonuç}

Kaynaştırma eğitimi, öğretimin önündeki engellerin kaldırılması ve bütün öğrencilerin eğitim ortamlarına entegrasyonunu içeren eğitim uygulamalarının düzenlenmesi sürecidir (Andreozzi ve Pietrocarlo, 2017). Avrupa toplulukları komisyonunun 2007 yllındaki raporunda, eğitim ortamlarındaki öğrencilerin farklı yetenek ve engel seviyelerine sahip bireylerden meydana gelen heterojen bir karışımdan oluştuğu belirtilmiştir. Ayrıca öğretmenlerin sürekli yeni bilgi ve beceriler ile kendini donatması gerektiği de ifade edilmiştir. Öte yandan sınıflardaki engelli bireylerin artması öğretmenleri daha karışık bir grubun eğitsel ihtiyaçlarına uymak için baskı altına almıştır (Hanushek ve Raymond, 2003). Öğretmenin kaynaştırma sınıflarındaki bireylerin eğitsel ihtiyaçlarını karşılamak için yeterliliği, öğrencilerde akademik ve sosyal becerilerde gelişme gibi olumlu sonuçları getirebilmektedir (Burstein, Sears, Wilcoxen, Cabello ve Spagna, 2004). Yapılan çalışmalar göstermektedir ki kaynaştırma eğitimi hem engelli öğrenciler için hem 
de normal öğrenciler için önem taşımaktadır. Ayrıca etkili kaynaştırma uygulamalarının yapılabilmesi için öğretmenlerin kaynaştırma eğitimine yönelik eğitim alması gerekebilmektedir. Dolayısıyla öğretmenlerin kaynaştırma eğitimine ilişkin mesleki ihtiyaçları incelenmesi gereken bir konudur.

Daha önce öğretmenlerin kaynaştırma eğitimine ilişkin eğitsel ihtiyaçlarını araştıran çalışmalar yapılmış olmasına rağmen, bu çalışmaları bir araya getiren bir derleme çalışması yapılmamıştır. Bu sistematik derleme çalışması kapsamında, 2009-2020 yılları arasında öğretmenlerin kaynaştırma eğitimine yönelik hizmet içi eğitim ihtiyaçları üzerine yapılmış çalışmaların bir araya getirilerek incelenmesi ve farklı değişkenler ele alınarak makalenin değerlendirilmesi amaçlanmıştır. Çalışma kapsamında makaleler yayınlandıkları yıllara, çalışmaların yapıldığ 1 ülkelere, kullanılan araştırma modellerine ve kullanılan araştırma yöntemlerine olmak üzere dört ana başlık altında incelenmiştir. Alanyazına ilişkin çalışmalar yayınlanma yıllarına göre incelendiğinde, 2014, 2017, 2019 ve 2020 yıllarında yapılan çalışmalar fazlalıkta görünmektedir. İncelenen çalışmalarda ağırlıklı olarak nicel çalışma deseninin $(\% 58,3)$, nitel çalışma desenine $(\% 43,, 7)$ kıyasla daha fazla tercih edildiği görülmüş̧ür. Çalışmalar kullanılan araştırma yöntemlerine göre ele alındığında ise, alanyazına ilişkin en çok tercih edilen desenin tarama deseni $(\% 33,3)$ olduğu bulunmuştur. Alanyazın taraması sonucunda, mevcut konu üzerine araştırma yapan ülkeler arasında Türkiye, Gana, İspanya, Malawi, Namibia, Zimbabwe, Amerika, Brezilya ve İskoçya bulunmaktadır. En düşük örneklemin Türkiye'de yapılmış olan çalışmada (20 kişi) bulunduğu dikkat çekmektedir. En büyük örneklem Malawi, Namibia ve Zimbabwe'de yapılmış olan çalışmada olmakta olup, çalışma toplam 629 kişiden oluşmaktadır. Öte yandan alanyazına ilişkin çalışmaların en sık yapıldığ 1 ülkenin Türkiye $(\% 41,6)$ olduğu ortaya çıkmıştır.

Alanyazın taraması sonucunda görülmüştür ki, öğretmenlerin kaynaştırma eğitimine yönelik hizmet içi eğitim ihtiyaçları konusunda birçok eğitsel ihtiyaç ortaya çıkmaktadır. Öğretmenler, özel gereksinimli öğrencilerin karakteristik ve gelişimsel özellikleri ile ilgili eğitimler, davranış kontrolü eğitimi, BEP hazırlama eğitimi, farklı eğitsel ihtiyaçları olan öğrencilere yönelik eğitimler, genel özel eğitime yönelik eğitimler, 
öğrenme güçlügüne yönelik eğitimler, duyusal engellerle ilgili eğitimler, davranış kontrolü eğitimleri, konularında mesleki eğitimlere ihtiyaç duyduklarını belirtmişlerdir. Ayrıca öğretmenlerin özel gereksinimli öğrencilerin eğitiminde kullanılacak destek materyalleri (oyunlar, cihazlar, yazılımlar ve yardımcı teknolojiler) konusunda eğitim alması gerektiği belirtilmiştir. Aynı zamanda öğretmenlerin kaynaştırma öğrencilerine yönelik genel öğretim yöntemleri ve stratejileri konusunda bilgi eksiklikleri olduğu ifade edilmiştir. Öte yandan, öğretmenler mesleki eğitimleri sürecinde kaynaştırma eğitiminin yeterli biçimde ele alınmamış olduğunu belirtmiş, bundan ötürü kaynaştırma eğitimine yönelik yetersizlik hissettiklerini iifade etmişlerdir. Ayrıca, eğitimciler öğretmen eğitimlerindeki eksikliklerden dolayı özel gereksinimli öğrencilere ilişkin özgüven yetersizliği yaşadıklarını belirtmişlerdir.

İncelenen çalışmaların \%50'sinde eğitimciler kaynaştırma eğitimine yönelik eğitime ihtiyaç duyduklarını belirtmişlerdir. Çalışmaların \%33,3'ünde eğitimciler özel gereksinimli öğrencilere ilişkin eğitim konusunda ve davranış kontrolü konularında eksiklik hissettiklerini ifade etmişlerdir. Ayrıca incelenen çalışmaların \%25'inde öğretmenlerin kaynaştırma eğitiminde alternatif değerlendirme araçları, öğrenme güçlüğü konularında eğitim almak istedikleri ve öğretmenlere yönelik beceri eğitimi konusunda hizmetiçi eğitim almak istedikleri ortaya çıkmıştır.

Öğretmenler coğrafi konum itibariyle kaynaştırmaya yönelik yeterlilikleri incelendiğinde, şehirde çalışan öğretmenlerin, kaynaştırma öğretimi için bilgi ve becerilerinin yetersiz olduğunu belirttikleri ve öğretmenlik eğitimleri konusunda oldukça olumsuz görüşlere sahip oldukları ortaya çıkmıştır. Alanyazın incelendiğinde, ilişkili makalelerin hepsinde de eğitimcilerin kaynaştırma eğitiminde daha etkili olabilmesi için, engel türlerine yönelik eğitimlere ihtiyaç duydukları belirtilmiştir.

Bu çalışma kapsamında, Semantic Scholar, ERIC ve Researchgate veri tabanlarında tarama yapılmıştır. Ayrıca taranan makaleler 2009-2020 yılları arasını kapsamaktadır. Öğretmenlerin kaynaştırma eğitimine yönelik ihtiyaçlarının önemi göz önünde bulundurulduğunda, alanyazına ilişkin yapılacak çalışmalarda bu bilgilerden yararlanılmasının uygun olacağı düşünülmektedir. 
EXTENDED ABSTRACT

\title{
Professional Development Needs of Educator Regarding Inclusive Education
}

\author{
İrem Girgin \\ MONE
}

Inclusive education is the process of regulating educational practices that include removing barriers to teaching and integrating all students into educational environments. Inclusive education is also an effective way for both disabled and non-disabled students to fulfill their full potential in academical and social fields. It is important to find out teachers' professional needs for inclusive education to increase the effectiveness of inclusion. In the report of the Commission of the European Communities in 2007, it was stated that the students in the education environment are a heterogeneous mixture of individuals with different abilities and disability levels. It was also stated that teachers should constantly equip themselves with new knowledge and skills to be able to aid different type of students. On the other hand, it is revealed that the increase of disabled students in the classrooms has put teachers under pressure to comply with the educational needs of a more mixed group. Improved proficiency of teachers that meet the educational needs of the individuals in the inclusive classrooms can bring positive results such as improvement in students' academic and social skills. Therefore, the professional needs of teachers regarding inclusive education is an issue that needs to be examined.

Systematic review method was used to evaluate the articles related to the effects of inclusive education. Systematic reviews are valuable studies since they consist of bringing the related studies together and reveal the keypoints in the literature. Within the scope of the study international studies that has been published between the years 20122020 were used. The keywords 'teachers' educational needs", "inclusive education" were scanned on ERIC, Semantic Scholar, and Reserachgate databases. As a result of the scanning process, the studies unrelated to the literature and the studies unsuitable to the aim of this study were 
eliminated, therefore 12 studies were examined in this systematic review study. Chosen studies were examined in six main areas: the educational needs of teachers, the analysis of the educational needs, year of publication, countries, research methods and types of the studies.

As a result of the study, it is revealed that the studies related to the literature were mostly conducted in the years 2014, 2017, 2019 and 2020. On the other hand it was observed the quantitative study design (58.3\%) was preferred more than the qualitative study design (43.7\%). To add more, the most preferred research model was found to be the scanning design (33.3\%).

Studies related to the topic were mainly conducted in Turkey, Ghana, Spain, Malawi, Namibia, Zimbabwe, America, Brazil and Scotland. It is noteworthy that the lowest sample found in the study was conducted in Turkey (20 people). The largest sample in the study was conducted in Malawi, Namibia and Zimbabwe, and the study consisted of a total of 629 people. On the other hand, it has been revealed that the country where studies on the literature are done most frequently is Turkey (41.6\%).

In $50 \%$ of the studies examined, educators stated that they needed training for inclusive education. In $33.3 \%$ of the studies, educators stated that they expressed they felt a lack of education and had some problems with behavior control for students with special needs. In addition, in $25 \%$ of the studies examined, it was revealed that teachers wanted to receive training on alternative assessment tools and learning disabilities in inclusive education, and they wanted to receive in-service training on skills training for teachers.

The teachers' qualifications for inclusion in terms of geographical location revealed that, teachers working in the city stated that their knowledge and skills were insufficient for inclusion teaching and they had very negative views on their teacher education. Also, it was stated in reviewed articles that educators needed training on disability types in order to be more effective in inclusive education.

As a result of the literature review, it is revealed that many educational needs arise regarding the in-service training needs of teachers for inclusive education. Teachers had expressed they needed vocational trainings on the following areas: characteristics and 
developmental characteristics of students with special needs, behavior control training, IEP preparation education, trainings for students with different educational needs, trainings for general special education, trainings for learning disabilities, trainings about sensory disabilities, behavior control training. In addition, it was stated that teachers should receive training on classroom support materials (games, devices, software and assistive technologies) to be used in the education of students with special needs. At the same time, it was stated that teachers lacked knowledge about general teaching methods and strategies for inclusive education.

\section{Kaynakça / References}

Akalın, S., Demir, Ş., Sucuoğlu, B., Bakkaloğlu, H. ve İşcen, F. (2014). The needs of inclusive preschool teachers about inclusive practices. Eurasian Journal of Educational Research, 54, 39-60.

Aktan, O. (2020). Determination of educational needs of teachers regarding the education of inclusive students with learning disability. International Journal of Contemporary Educational Research, 7(1), 149164.

Andreozzi P. and Pietrocarlo A. (2017). Educational Inclusion and Organization. In: Dovigo F. (eds) Special Educational Needs and Inclusive Practices. Studies in Inclusive Education. SensePublishers, Rotterdam.

Aslan, Y. G. (2020). Experiences of Turkish Preschool Teachers for including children with autism spectrum disorders: Challanges faced and methods used. International Journal of Psychology and Educational Studies, 7(2),37-49.

Berry, R. A. W. (2009). Voices of experience: General education teachers on teaching students with disabilities, 15(6), 627-648.

Brownell, M. T. V. and Pajares, F. (1999). Teacher efficacy and perceived success in mainstreaming students with learning and behaviour problems. Teacher Education and Special Education, 22(3), 154-164.

Burstein, N., Sears, S., Wilcoxen, A., Cabello, B. and Spagna, M. (2004). Moving towards inclusive practices. Remedial and Special Education,25(2), 104-116. 
Chitiyo, M., Hughes, E. M., Chitiyo, G., Changara, D. M., Phiri, A. I., Haihambo, C., Taukeni, S. G. and Dzenga, C. G. (2019). Exploring teachers' special and inclusive education professional development needs in Malawi, Namibia and Zimbabwe. International Journal of Whole Schooling, 15(1),28-49.

Chitiyo, M., Kumedzro, F. K., Hughes, E. M. and Ahmed, S. (2019). Teachers' professional development needs regarding inclusive education in ghane. International Journal of Whole Schooling, 15(2),53-79.

Cole, C. M., Waldron, N. and Majd, M. (2004). Academic progress of students across inclusive and traditional settings. Mental Retardation, 42(2), 136-144.

Commission of the European Communities (2007). Communication from the Commission to the Council and the European Parliament: Improving the quality of teacher education. https://eurlex.europa.eu/legalcontent/EN/TXT/PDF/?uri=CELEX:520 07DC0392\&from $=\mathrm{EN}$

Çakıroğlu, A. ve Kuruyer, H. G. (2017). Sınıf öğretmenlerinin özel öğrenme güçlüğü olan öğrencilerin eğitsel değerlendirme ve eğitsel müdahale sürecinde görüş ve uygulamaları. International Periodical for the Languages, Literature and History of Turkish or Turkic, 12(28), 539-555.

Ergin, İ., Akseki, B. ve Deniz, E. (2012). İlköğretim okullarında görev yapan sınıf öğretmenlerinin hizmet içi eğitim ihtiyaçları. Elektronik Sosyal Bilimler Dergisi, 11(42), 55-66.

Ferguson, D. L. (1996). Is it inclusion yet? Bursting the bubbles. In M. S. Berres, D. L.

Ferguson, P. Knoblock, and C. Woods (1996). Creating tomorrow's schools today: Stories of inclusion, change, and renewal, New York, NY: Teaches College Press.

Ferguson, D. L., Kozleski, E. B. and Smith, A. (2003). Transformed, inclusive schools: A frame- work to guide fundamental change in urban schools. Effective Education for Learners with Exceptionalities, 15, 4374.

Ferriday, G. and Cantali, D. (2020). Teachers talk about inclusion...but can they implement it in their classroom? Exploring teachers' views on inclusion in a Scottish secondary school. Support for Learning, 35(2),144-162. 
Flem, A., Moen, T. and Gudmundsdottir, S. (2004). Towards inclusive schools: A study of inclusive education in practice. European Journal of Special Needs Education, 19(1), 85-98.

Florian, L. and Rouse, M. (2009). The inclusive practice project in Scotland: Teacher education inclusive education, Teaching and Teacher Education, 25, 594-601.

Friend, M. (2007). The co-teaching partnership. Educational Leadership, 64(5), $48-51$.

Gameros, P. (1995). The visionary principal and inclusion of students with disabilities. NASSP Bulletin, 79(568), 15-17.

Hammond, L. D. (1998). Teacher learning that supports student learning, Educational Leadership, 55(5), 6-11.

Hansen, J. H., Carrington, S., Jensen, C. R., Molbæk, M. and Secher Schmidt, M. C. (2020). The collaborative practice of inclusion and exclusion. Nordic Journal of Studies in Educational Policy, 6(2), 1-11.

Hanushek, E. A. and Raymond, M. E. (2003). Improving educational quality: How best to evaluate our schools? In Y. Kodrzycki (Ed.), Education in the 21st century: Meeting the challenges of a changing world (p.193-224). Boston, MA: Federal Reserve Bank of Boston.

Hart, C. (2001). Doing a Literature Review, London: Sage Publications.

Holloway, J. H. (2001). Inclusion and students with learning disabilities. Educational Leadership, 58(6), 86-88.

Hornby, G. (2011). Inclusive education for children with special educational needs: A critique. International Journal of Disability, Development and Education, 58(3), 321-329.

Manrique, A. L., Dirani, E. A. T., Frere, A. F., Moreira, G. E. and Arezes, P. M. (2018). Teachers' perceptions on inclusion in basic school, International Journal of Educational Management, 33(2)9,409-419.

Majoko, T. (2017). Zimbabwean early childhood education special needs education teacher preparation for inclusion. International Journal of Special Education, 32(4),671-696.

MEB (2008). Sınıf öğretmenlerinin hizmet içi eğitim ihtiyacının belirlenmesi. Ankara.

Mittler, P. (2000). Working towards inclusive social contexts. London: David Fulton. 
Moreno, J. A. C., Jaén, M. D. M., Navío, E. P. and Moreno, J. R. (2015). Inclusive education in schools in rural ares. New Approaches in Educational Research, 4(2), 107-114.

Moriña, A., Perera and Carballo, R. (2020). Training needs of academics on inclusive education and disability. Sage Journals, 10(3), 1-10.

Mulrow, C. D. (1994). Rationale for systematic reviews. BMJ, 309, 597-599.

Nakken, H. and Pijl, S. J. (2002). Getting along with classmates in regular schools: A review of the effects of integration on the development of social relationships. International Journal of Inclusive Education, 6, 4761.

Pinar, E. S. (2014). Identification of inclusive education classroom teachers' views and needs regarding in-service training on special education in Turkey. Educational Research and Reviews,9(20), 1097-1108.

Rea, P. J., McLaughlin, V. L and Walther-Thomas, C. (2002). Outcomes for students with learning disabilities in inclusive and pullout programs. Exceptional Children, 68, 203-222.

Rose, D., Meyer, A. and Hitchcock, C. (2011). The universally designed classroom: Accessible curriculum and digital technologies. Cambridge, MA: Harvard Education Press.

Sebba, J. and Sachdev, D. (1997). What works in inclusive education? Ilford: Barnardo's.

Stella, C. S. C., Forlin, C. and Lan, A. M. (2007). The influence of inclusive education course on attitude change of pre-service secondary teacher in Hong-Kong, Asia Pacific Journal of Teacher Education, 35(2), 161-179.

Synder, R. F. (1999). Inclusion: A qualitative study of inservice genereal education teachers' attitudes and concerns. Education,120(1),173.

Tkachyk, R. E. (2013). Questioning secondary inclusive education: Are inclusive classrooms always best for students ? Interchange, 44, 1524.

Vaughn, S. and Swanson, E. (2015). Special education research advances knowledge in education. Exceptional Children, 82(1), 11-24. 


\section{Kaynakça Bilgisi / Citation Information}

Girgin, İ. (2021). Eğitimcilerin kaynaştırmaya yönelik mesleki gelişim ihtiyaçları. OPUS-Uluslararası Toplum Araştırmaları Dergisi, 18(Eğitim Bilimleri Özel Sayıs1), 4151-4175. DOI: 10.26466/ opus.845376. 